\title{
Simultaneous Computed Tomography-Guided Biopsy and Radiofrequency Ablation of Solitary Pulmonary Malignancy in High-Risk Patients
}

\author{
T. Schneider $^{a} \quad$ M. Puderbach ${ }^{b} \quad$ J. Kunz ${ }^{b} \quad$ A. Bischof ${ }^{b} \quad$ F.L. Giesel ${ }^{e}$ \\ H. Dienemann ${ }^{a}$ F.J.F. Herth ${ }^{c}$ P.A. Schnabel ${ }^{d}$ S. Safi ${ }^{a}$ H. Hoffmann ${ }^{a}$ \\ C.P. Heussel ${ }^{b}$

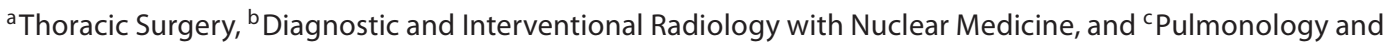 \\ Critical Care Medicine, Thoraxklinik, ${ }^{\mathrm{d}}$ Department of General Pathology, Institute of Pathology, and \\ e Department of Nuclear Medicine, Heidelberg University, Heidelberg, Germany
}

\section{Key Words}

Biopsy $\cdot$ Chest CT $\cdot$ Chest interventions $\cdot$ Interventional radiology $\cdot$ Lung cancer treatment $\cdot$ Pulmonary nodules

\begin{abstract}
Background: In recent years experience has been accumulated in percutaneous radiofrequency ablation (RFA) of lung malignancies in nonsurgical patients. Objectives: In this study, we retrospectively evaluated a simultaneous diagnostic and therapeutic approach including CT-guided biopsy followed immediately by RFA of solitary malignant pulmonary lesions. Methods: CT-guided transthoracic core needle biopsy of solitary pulmonary lesions suspicious for malignancy was performed and histology was proven based on immediate frozen sections. RFA probes were placed into the pulmonary tumors under $\mathrm{CT}$ guidance and the ablation was performed subsequently. The procedure-related morbidity was analyzed. Follow-up included a CT scan and pulmonary function parameters. Results: A total of 33 CT-guided biopsies and subsequent RFA within a single procedure were performed. Morbidity of CT-guided biopsy included pulmonary hemorrhage (24\%) and a mild pneumothorax (12\%) without need for further interventions. The RFA procedure was not
\end{abstract}

aggravated by the previous biopsy. The rate of pneumothorax requiring chest tube following RFA was $21 \%$. Local tumor control was achieved in 77\% with a median follow-up of 12 months. The morbidity of the CT-guided biopsy had no statistical impact on the local recurrence rate. Conclusions: The simultaneous diagnostic and therapeutic approach including CT-guided biopsy followed immediately by RFA of solitary malignant pulmonary lesions is a safe procedure. The potential of this combined approach is to avoid unnecessary therapies and to perform adequate therapies based on histology. Taking the local control rate into account, this approach should only be performed in those patients who are unable to undergo or who refuse surgery.

Copyright $\odot 2012$ S. Karger AG, Basel

\section{Introduction}

In the general population, the prevalence of malignancy in newly detected solitary pulmonary lesions (SPL) is approximately $60 \%[1,2]$. In patients with a history of cancer, a rate of up to $90 \%$ malignancy in newly detected SPL has been reported [3]. Currently, positron emission tomography (PET) [4] is the most specific radio-diagnos-

\section{KARGER \\ Fax +41613061234 \\ E-Mail karger@karger.ch}

www.karger.com (c) 2012 S. Karger AG, Basel

0025-7931/12/0846-0501\$38.00/0

Accessible online at:

www.karger.com/res
Thomas Schneider, MD

Thoraxklinik, Heidelberg University

Amalienstrasse 5

DE-69126 Heidelberg (Germany)

E-Mail thomas.schneider@thoraxklinik-heidelberg.de 
Table 1. Patients were excluded from surgery due to the following comorbidities

\begin{tabular}{lr}
\hline Comorbidity & $\mathrm{n}$ \\
\hline Severely limited pulmonary function & \\
$\quad \quad$ pred. $\mathrm{FEV}_{1}<40 \%$ or diffusion capacity $\left.<40 \%\right)$ & 16 \\
Severe cardiac risk (NYHA III, LVEF depression) & 13 \\
6-min walking test $<150$ m & 12 \\
Previous lung resection & 6 \\
Previous thoracic radiotherapy & 4 \\
Very limited ability of cooperation (ECOG $>2)$ & 5 \\
Multiple comorbidities & 18 \\
\hline
\end{tabular}

tic tool, but false-positive results in nonmalignant pulmonary lesions such as inflammatory lesions and granulomatous diseases limit its clinical value [5-7]. However, histologic proof of SPL should be standard prior to any treatment. Innovative endoscopic approaches (endobronchial ultrasound or navigation systems) can yield a histologic diagnosis in up to $80 \%$ in SPL with a diameter of less than $30 \mathrm{~mm}$ [8-10]. In many centers CT-guided biopsy is the diagnostic procedure of choice with expected diagnosis of malignancy for tumors greater than $1 \mathrm{~cm}$ over $90 \%$ [11]. If both diagnostic tools fail to prove a diagnosis, surgical resection is the preferred diagnostic and therapeutic approach in patients who are appropriate for surgery [3, 12]. In recent years, increasing experience has been gained in percutaneous radiofrequency ablation (RFA) as a minimal invasive technique in nonsurgical patients with promising oncological results and a tolerable morbidity related to the intervention [13-15]. In this study, we retrospectively evaluated a simultaneous diagnostic and therapeutic approach including CT-guided biopsy for histologic proof based on frozen sections, followed immediately by RFA of solitary malignant pulmonary lesions in nonsurgical candidates.

\section{Methods}

A total of 28 patients with the radiologic finding of an SPL that is suspicious for malignancy were included in this retrospective analysis. The median diameter of the SPL was $23 \mathrm{~mm}$ (range 10$35 \mathrm{~mm}$ ). Endoscopy, including endobronchial ultrasound, failed to provide proof of malignancy; PET-CT has shown a significant FDG uptake in the pulmonary nodule, whereas mediastinal and hilar lymph nodes lacked detectable FDG uptake. No cerebral metastases were observed on contrast-enhanced cerebral MRI or CT. All subjects were introduced personally to a thoracic surgeon and inoperability was determined due to limited pulmonary function or other comorbidities (table 1). Furthermore, all subjects were discussed in the interdisciplinary tumor board (thoracic surgeon, pulmonologist, medical oncologist, radiation oncologist, diagnostic and interventional radiologist, pathologist, anesthesiologist) and a minimally invasive interventional approach (CT-guided biopsy for proof of histology and subsequent therapeutic ablation within a single procedure) was considered to be appropriate.

Seven patients had a history of non-small cell lung cancer (NSCLC; lobectomy $\mathrm{n}=1$; radiotherapy due to limited pulmonary function $\mathrm{n}=5$; lobectomy + radiotherapy $\mathrm{n}=1) ; 8$ patients had a history of other malignancies (prostatic cancer $\mathrm{n}=3$; endometrial cancer $n=1$; soft tissue sarcoma $n=2$; oropharyngeal cancer $n=2$ ).

All patients underwent general anesthesia and endobronchial double-lumen intubation before lung biopsy. According to the lesion localization, the patient was placed in a supine or prone position. Under CT guidance transthoracic core needle biopsy (Automatic BARD ${ }^{\circledR}$ Magnum biopsy system MG 1522 , BARD ${ }^{\circledR}$ coaxial needle $18 \mathrm{G} \mathrm{C1820B}$ ) was performed (fig. 1a). One tissue sample was immediately sent to the pathologist for immediate frozen section and further samples were taken if needed for subsequent additional diagnostics (immunochemistry or molecular pathology). Histology was proven based on immediate frozen section within approximately $10 \mathrm{~min}$ of the core-cut biopsy. If no malignancy was detected in the first sample, up to two further tissue samples were sent to the pathologist. The cannula of the biopsy system remained in situ while awaiting the results of frozen section examination. If another biopsy was requested by the pathologist, it was taken via this cannula. After successful proof of malignancy, the cannula of the biopsy system was removed and a CT scan was performed for biopsy-related complications. The RFA probe was placed under CT guidance into the pulmonary tumor (fig. 1b). A limited pneumothorax, which was not progressive during the RFA procedure, was tolerated. Indication for chest tube placement was progressive pneumothorax with consecutive aggravation of correct RFA probe placement or clinical symptoms of the patient.

The technique of RFA depended on the tumor size according to the manufacturer's recommendation. Bipolar RFA (Celon LABPower; single bipolar Celon ${ }^{\circledR}$ ProSurge RFA probe) was performed using a single probe in tumors that were up to $2.0 \mathrm{~cm}$ in diameter, and multipolar RFA (Celon ${ }^{\circledR}$ LABPower; multiple bipolar Celon ${ }^{\circledR}$ ProSurge RFA probes) was performed in tumors with a diameter ranging from 2.0 to $3.0 \mathrm{~cm}$. Monopolar RFA (Boston Scientific ${ }^{\circledR}$ RF 3000; LeVeen 3-cm RFA probe) was performed in tumors with a diameter of $>3 \mathrm{~cm}$. After the application of the approved amount of thermal energy, the RFA probes were removed and a nonenhanced CT scan was performed to detect immediate complications. A chest radiograph was obtained $3 \mathrm{~h}$ later after extubation to assess the occurrence of complications, such as pneumothorax, hemothorax and pleural effusion. If a progressive pneumothorax was seen on the first chest radiograph, a chest tube was placed. If the pneumothorax was not progressive over time or a newly detected pneumothorax caused no symptoms, a second chest radiograph was performed $2 \mathrm{~h}$ later. A chest tube was placed if the patient was symptomatic or the pneumothorax was progressive.

Due to the patients' comorbidity, all subjects were observed after the intervention for at least $24 \mathrm{~h}$ in the intensive care unit and underwent a nonenhanced follow-up CT scan the next day to document potential early adverse events. 


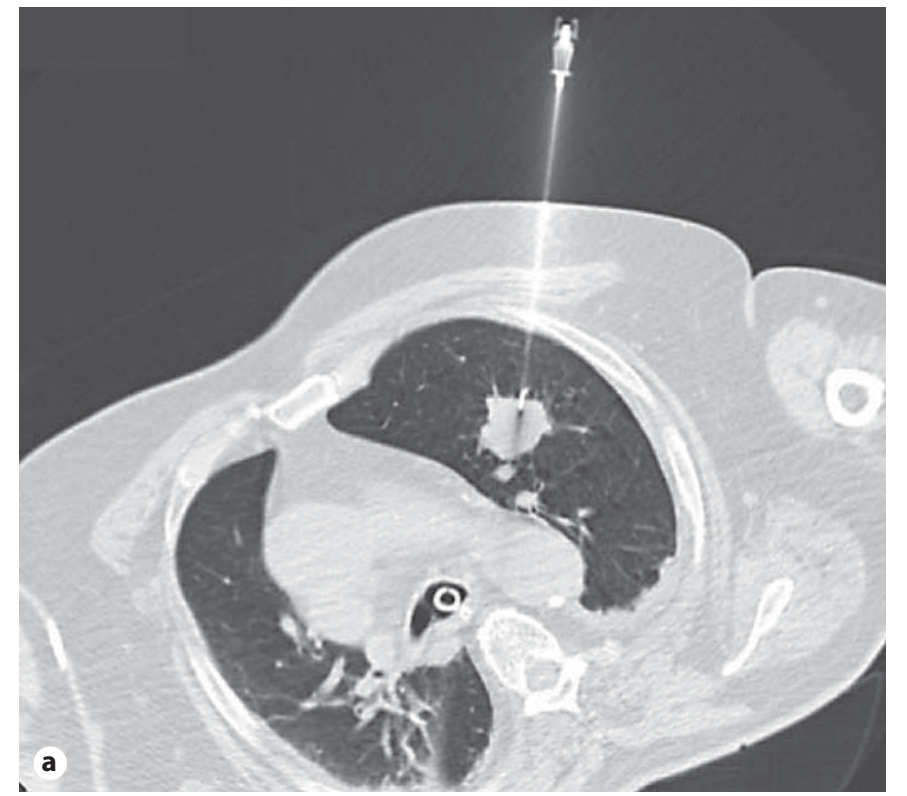

Fig. 1. a CT-guided core needle biopsy in a patient with severely limited pulmonary function $\left(\mathrm{FEV}_{1}=0.8\right.$ liters $)$. $\mathbf{b}$ Monopolar RFA after proof of histology (NSCLC). c Follow-up CT scan 3 months after RFA: the ablated tumor tissue has shrunk in diameter.

Follow-up investigations at 1,2 and 3 months after RFA and subsequently at 3-month intervals included clinical investigation, pulmonary function parameters $\left(\mathrm{VC}\right.$ and $\mathrm{FEV}_{1}$ ) and contrast-enhanced CT scan (fig. 1c, 2d). In case of local progression the patient underwent PET-CT.

Statistical analysis of the procedure-related morbidity was performed by Fisher's exact test using GraphPad Prism statistical software (GraphPad Software, La Jolla, Calif., USA).

The Ethics Committee of the University of Heidelberg approved this retrospective study (080/2006). The procedures to be undertaken were thoroughly explained to each subject and written informed consent was obtained prior to the intervention.

CT-Guided Biopsy and RFA of Solitary Pulmonary Lesions
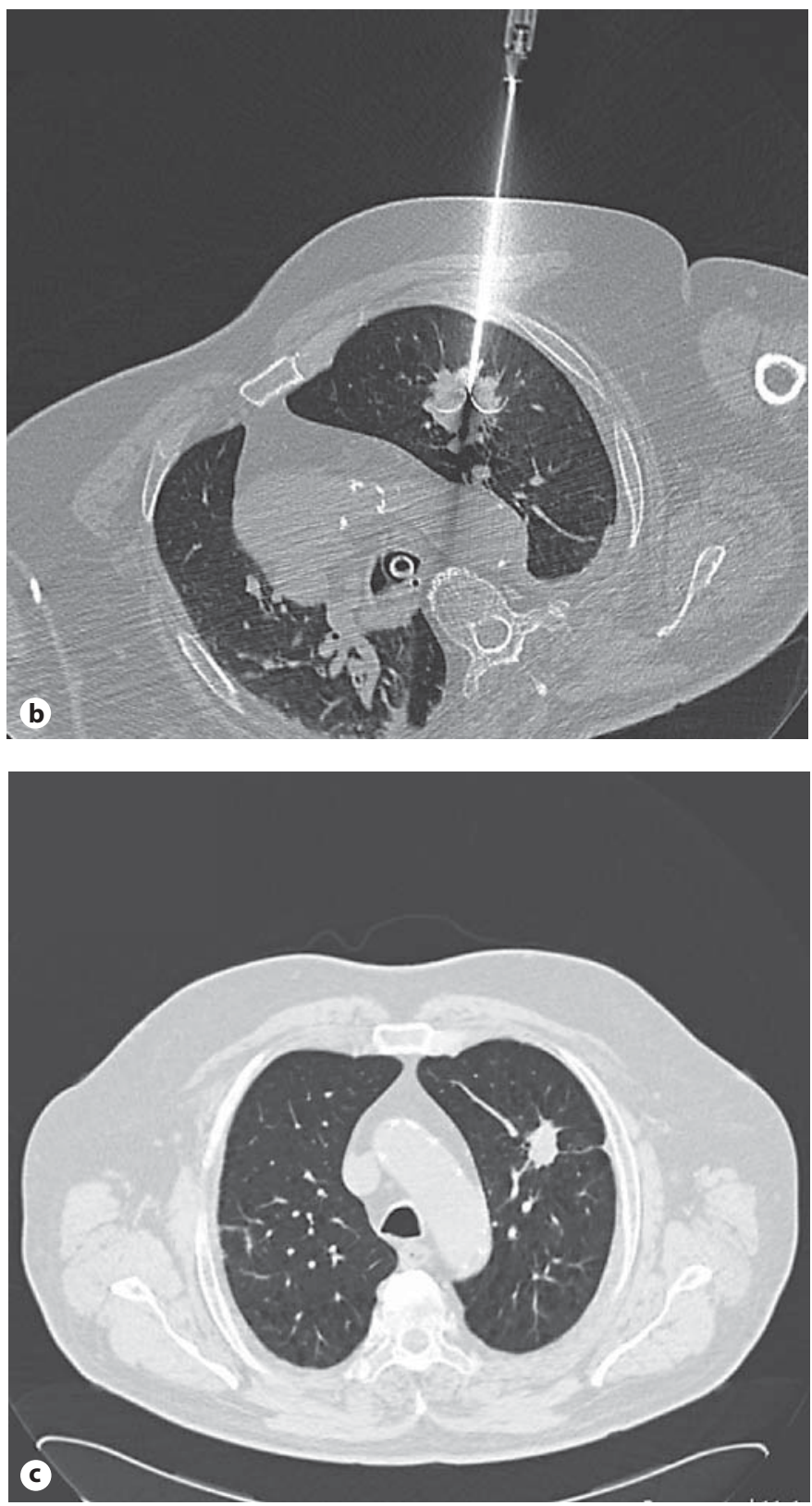

\section{Results}

During the 2-year period (November 2009 to October 2011), a total of 28 subjects (20 male, 8 female; median age 71 years, range $42-83$ ) with the radiologic finding of a solitary pulmonary nodule underwent CT-guided biopsy with proof of malignancy based on the frozen section and subsequent RFA of the pulmonary lesion. A total of 5 subjects underwent the procedure repeatedly (local recurrence on PET/CT in $\mathrm{n}=3$; new development of a contra- 

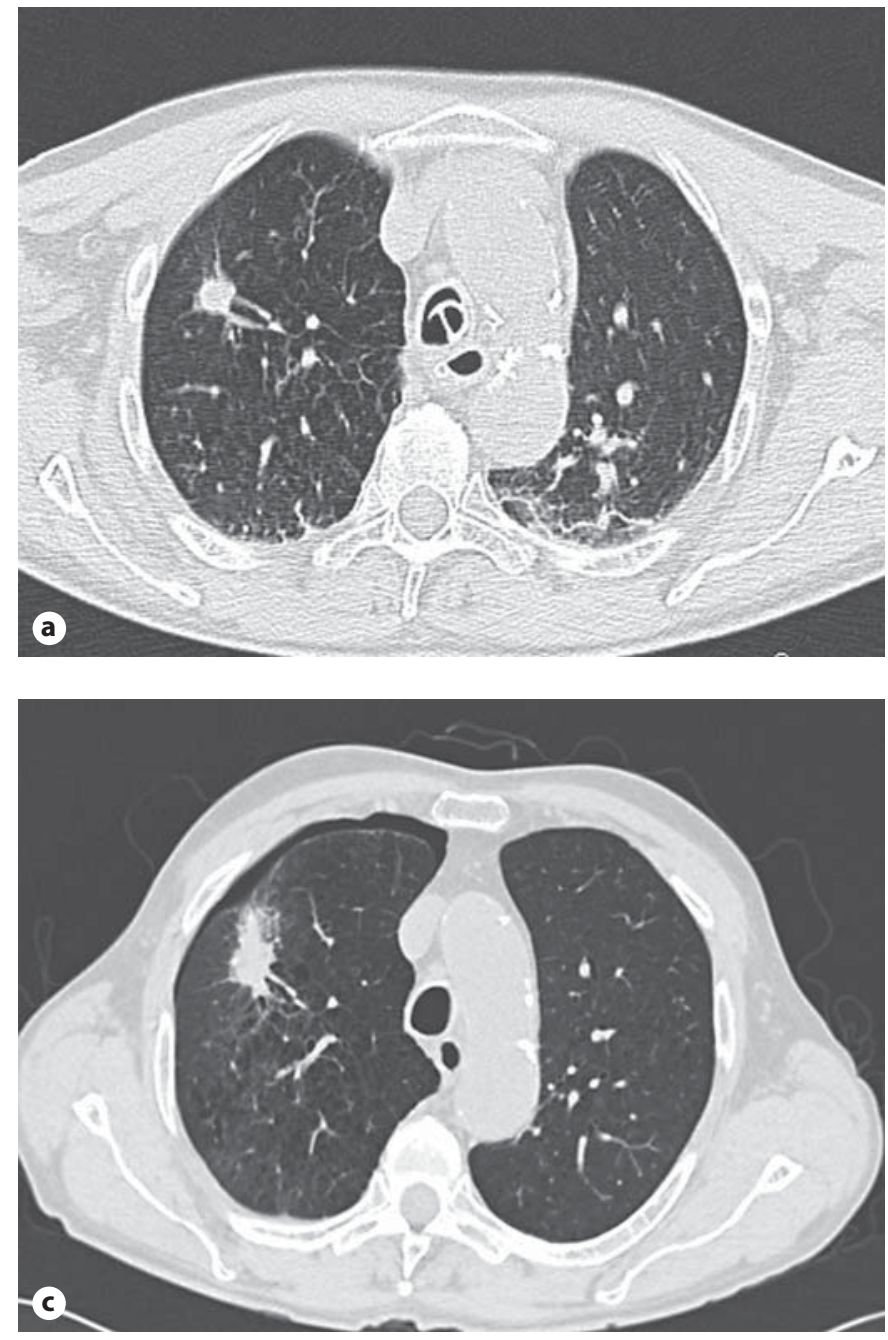

Fig. 2. a Baseline CT scan: pulmonary lesion with a diameter of $2 \mathrm{~cm}$. b Parenchymal hemorrhage in the tumor-surrounding lung tissue developing during bipolar RFA. c Control CT scan 1 day subsequent to RFA: the parenchymal hemorrhage has mean-

lateral solitary pulmonary lesion in $\mathrm{n}=2$ ). Thus, a total of 33 CT-guided biopsies and subsequent RFA within a single procedure were performed in a total of 30 pulmonary lesions (monopolar RFA $\mathrm{n}=5$, bipolar RFA $\mathrm{n}=17$, multipolar RFA $\mathrm{n}=11$ ). The median tumor diameter was $2.3 \mathrm{~cm}$ (range 1.0-3.5 cm). The median duration of the RFA procedure was $45 \mathrm{~min}$ (range 19-92 min). The median duration of general anesthesia including patient positioning, CT-guided biopsy, immediate frozen section and placement of RFA probes was 135 min (range 60-225 $\mathrm{min})$. No complications related to general anesthesia were observed. The median stay in the intensive care unit after the intervention was 1 day (range 1-3 days).
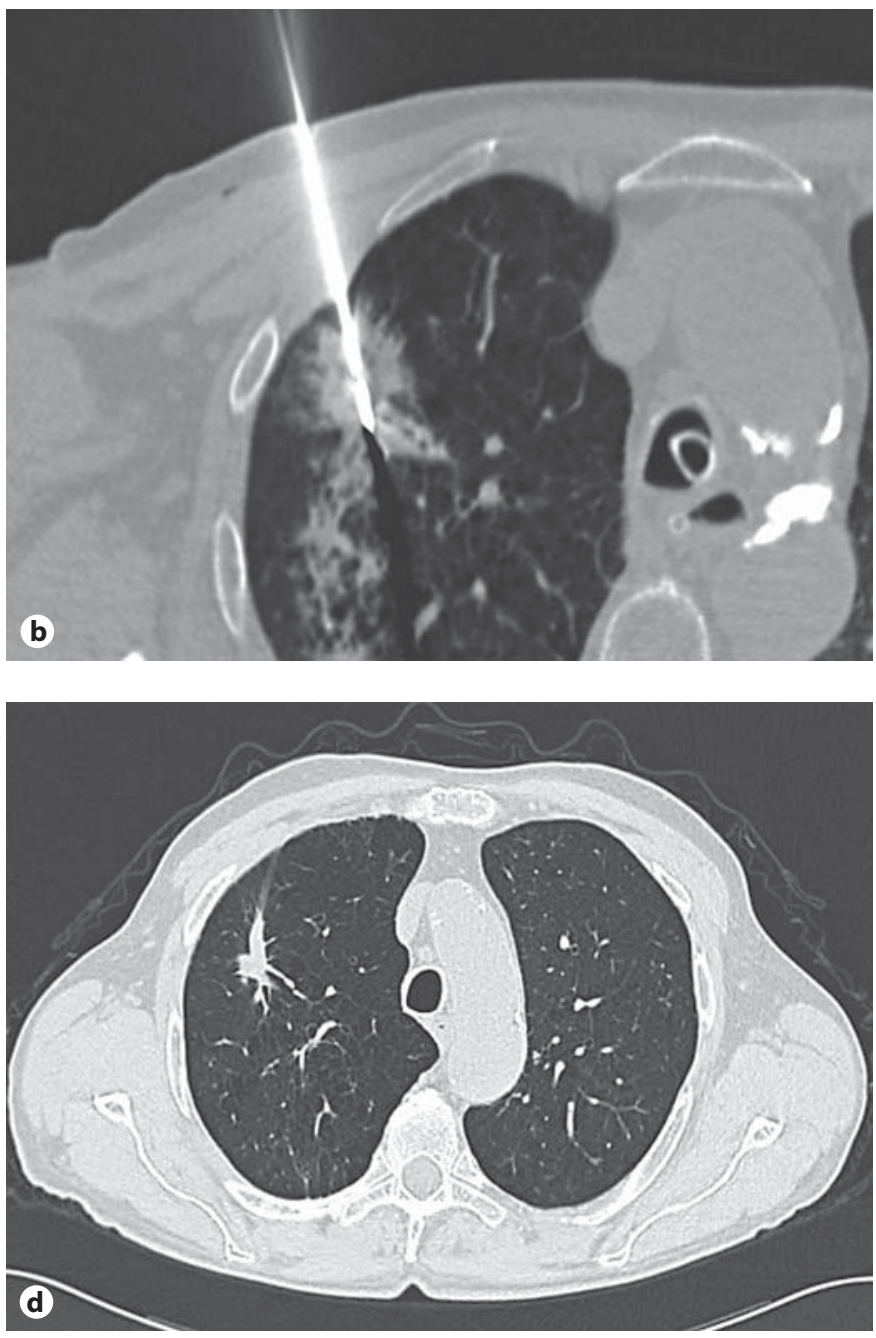

while been mainly resorbed. The procedure related to mild and constant pneumothorax did not require drainage. d Control CT scan 3 months subsequent to RFA: further contraction of the ablated area indicates local tumor control.

Malignancy was verified with CT-guided core cut biopsy and immediate frozen section in all patients. In a total of 21 procedures, one tissue probe was sufficient for diagnosis, a second tissue probe was required in 8 cases and three tissue probes were necessary in 4 cases. In a total of 28 biopsies, frozen section verified NSCLC. Pulmonary metastases were detected in a total of 4 patients with preexisting malignancies. Definite histology confirmed the result of the frozen section in a total of 32 biopsies (97\%). In 1 patient with preexisting NSCLC, malignancy was detected based on the frozen sections; however, definite histology did not confirm this finding. 
In a total of 8 patients (24\%) hemorrhage in the tumorsurrounding lung tissue was seen subsequent to core cut biopsy (mean tumor diameter $16 \mathrm{~mm}$ ). A mild pneumothorax requiring no drainage developed in a total of 4 procedures (12\%).

The RFA probes were successfully placed at the planned position within the pulmonary tumors in all patients. Neither local hemorrhage nor pneumothorax aggravated the correct probe placement. The appropriate amount of thermal energy was applied into the tumors. At the end of RFA, ground-glass parenchymal opacity surrounding the ablated tumors was observed in all patients.

In a total of 3 patients (9\%) pulmonary hemorrhage in the tumor-surrounding lung tissue was newly detected during RFA (fig. 2a, b). In a total of 7 patients (21\%) pneumothorax evolved during RFA. In a total of 3 patients (9\%) pneumothorax was newly detected on the first chest radiograph after extubation (fig. 2c). Chest tube placement was required in 1 patient (3\%) during RFA to avoid a dislocation of the RFA probe. In a total of 6 patients (18\%) a chest tube was placed subsequent to RFA due to a collapse of the lung. All chest tubes were removed without further interventions after a median of 3 days (range: 2-5 days).

In a single subject, a pleural catheter was placed due to persisting pleural effusion for 4 days. One subject with a history of alcohol abuse and liver cirrhosis developed hemorrhage due to active bleeding at the ablation site. The concurrent hemothorax was evacuated, and the bleeding was stopped with surgical intervention via a mini-thoracotomy. Major and minor complications related to the RFA procedure are summarized in table 2. All patients were discharged in good clinical condition after a median of 6 days (range: 4-14 days); there was no 30day mortality.

In a total of 8 patients with NSCLC (24\%), local tumor recurrence was detected after a median follow-up period of 6 months based on an increase in the diameter of the ablated tumor tissue and high FDG uptake in PET-CT. Two subjects were not able to undergo repeated local therapy - they received the best supportive care. One patient underwent stereotactic irradiation. Two patients with systemic and local progression underwent systemic chemotherapy. Three patients were candidates for repeated RFA, and the PET-CT was also performed again. In the marginal zone of the initial ablation zone, a high FDG uptake was found. Consequentially, these patients underwent the repeated procedure. Unfortunately, local tumor control was achieved in only 1 of these patients. In the 2 remain-
Table 2. Morbidity related to CT-guided core needle biopsy and the RFA procedures

\begin{tabular}{llc}
\hline Morbidity & Biopsy, n & RFA, n \\
\hline $\begin{array}{llc}\text { Pleural effusion } \\
\text { Requiring pleuracentesis }\end{array}$ & 0 & $\begin{array}{c}13(39 \%) \\
1(3 \%)\end{array}$ \\
\hline Pneumonia & 0 & $2(7 \%)$ \\
\hline $\begin{array}{l}\text { Pneumothorax } \\
\text { Requiring chest tube }\end{array}$ & $4(12 \%)$ & $10(30 \%)$ \\
\hline Local parenchymal hemorrhage & $8(24 \%)$ & $3(21 \%)$ \\
\hline Hemothorax & 0 & $1(3 \%)$ \\
Requiring mini-thoracotomy & & $1(3 \%)$ \\
\hline
\end{tabular}

ing patients, local and systemic tumor progression was observed during further follow-up. Altogether, local tumor control was achieved in 23 lesions (77\%) with a median follow-up of 12 months. The clinical course of the subjects included in this study is summarized in figure 3 .

With regard to recurrence no statistically significant impact of biopsy-related hemorrhage [ $\mathrm{p}=1.0000$; odds ratio $(\mathrm{OR})=1.056]$, biopsy-related pneumothorax $(\mathrm{p}=$ $1.0000 ; \mathrm{OR}=1.048)$ and RFA-related pneumothorax $(\mathrm{p}=$ $0.6518 ; \mathrm{OR}=0.4524$ ) were found (table 3 ).

The pulmonary function parameters ( $\mathrm{VC}$ and $\mathrm{FEV}_{1}$ ), as measured at 1,2 and 3 months after RFA, remained unchanged compared with the baseline values before RFA [median $\mathrm{FEV}_{1}$ pre-RFA = 1.7 liter (56\% pred. value); 3 months post-RFA $=1.6$ liter ( $54 \%$ pred. value)].

\section{Discussion}

In this study, patients who were not candidates for surgery because of their comorbidity underwent CT-guided biopsy and subsequent CT-guided RFA of a solitary pulmonary lesion within a single session. To the best of our knowledge, this concurrent diagnostic and therapeutic approach has not been previously reported in the literature. The potential of this combined approach is to avoid unnecessary therapies and eventually perform adequate adjuvant therapies based on histology.

With regard to the high-risk profile of our patients, we decided to perform this hybrid approach (including both biopsy and ablation) under general anesthesia for better patient comfort, better positioning during the procedure and better ability to address any intraprocedural compli- 


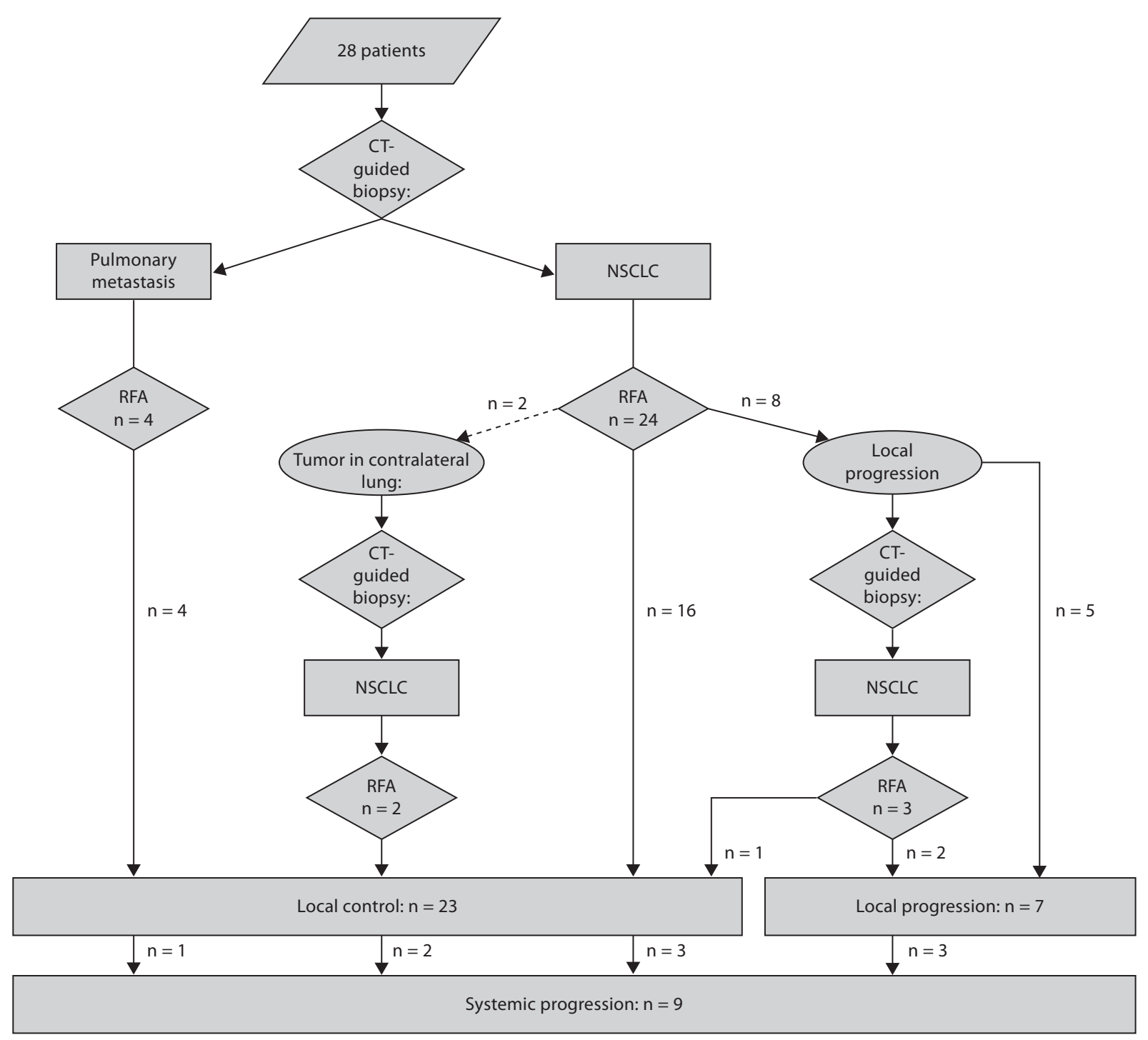

Fig. 3. Clinical course of the patients included in the study.

cations. Double-lumen intubation was chosen to protect the contralateral lung in case of local complications (e.g. hemorrhage). Since neither severe local hemorrhage nor significant pneumothorax were observed in our patients, we would agree that this approach may be seen as overprotective. We are considering realizing this approach in local anesthesia in the future.

CT-guided core needle biopsy was chosen to acquire a sufficient amount of tumor tissue to prove malignant diagnosis and be able to perform additional immunohisto- chemistry and molecular pathological investigations as well (EGFR gene mutation analysis or EML4 ALK fusion genes) [16]. In the literature the reported sensitivity of core needle biopsy ranges from 56 to $89 \%$ [17]. In clinical practice $31-82 \%$ of pulmonary nodules are malignant [18]; however, the high rate of malignant histology in this series (all lesions were malignant) is clearly the result of the strict selection of our patients. The radiologic features of growth and high FDG uptake in PET-CT were clear hints for malignancy. 
Table 3. Relationship between complicating factors (pneumothorax of hemorrhage) secondary to CT-guided core needle biopsy (CNB) or RFA and local recurrence of tumor

\begin{tabular}{|c|c|c|c|}
\hline & \multicolumn{2}{|l|}{ Groups } & \multirow[t]{2}{*}{ Strength of association } \\
\hline & $\begin{array}{l}\text { recurrence } \\
\text { of tumor, } n\end{array}$ & $\begin{array}{l}\text { no recurrence } \\
\text { n }\end{array}$ & \\
\hline $\begin{array}{l}\text { Pneumothorax due to CNB } \\
\text { No pneumothorax }\end{array}$ & $\begin{array}{l}1 \\
7\end{array}$ & $\begin{array}{r}3 \\
22\end{array}$ & $\begin{array}{l}\mathrm{p}=1.000 \\
\mathrm{OR}=1.048 \\
95 \% \mathrm{CI}=0.093-11.760\end{array}$ \\
\hline $\begin{array}{l}\text { Hemorrhage due to CNB } \\
\text { No hemorrhage }\end{array}$ & $\begin{array}{l}2 \\
6\end{array}$ & $\begin{array}{r}6 \\
19\end{array}$ & $\begin{array}{l}\mathrm{p}=1.000 \\
\mathrm{OR}=1.056 \\
95 \% \mathrm{CI}=0.167-6.682\end{array}$ \\
\hline $\begin{array}{l}\text { Pneumothorax due to RFA } \\
\text { No pneumothorax }\end{array}$ & $\begin{array}{l}1 \\
7\end{array}$ & $\begin{array}{r}6 \\
19\end{array}$ & $\begin{array}{l}\mathrm{p}=0.652 \\
\mathrm{OR}=0.452 \\
95 \% \mathrm{CI}=0.046-4.459\end{array}$ \\
\hline
\end{tabular}

The rates of local hemorrhage and pneumothorax after core needle biopsy in this series are in line with the literature $[19,20]$. Both complications may potentially limit the optimal placement of the RFA probes in small pulmonary lesions and therefore may serve as main disadvantage of the proposed hybrid approach. In this series, however, RFA probe placement was not aggravated and complications in terms of hemorrhage or pneumothorax had no significant impact on the local recurrence rate.

Pneumothorax during or subsequent to RFA in this series was also in line with the reported rates in the literature $[14,21]$ and had no impact on local recurrences as well. Furthermore, as a major complication, we observed a single hemothorax with the bleeding originating from the RF-probe insertion into the middle lobe. In the literature, hemothorax is infrequently reported [22, 23]. Pleural effusions as the minor complication are frequently reported in the literature (up to 55\%); however, only a few thoracenteses were needed, which is consistent with our findings [24, 25]. An expeditious and effective management of potential complications is indispensable in this group of high-risk patients; therefore, it is critical that the interventions are performed by a team that is following the patient very closely.

Local tumor control was achieved with this hybrid approach in $23(77 \%)$ patients. This rate is consistent with the local tumor control rate of RFA in the literature [14]. Hypofractionated stereotactic radiotherapy - in stage I NSCLC resulting in up to $85 \%$ local tumor control and up to $5 \%$ therapy-associated grade 2 toxicity - currently ri-

CT-Guided Biopsy and RFA of Solitary

Pulmonary Lesions vals RFA [17, 26, 27]. Unfortunately, to date, no prospective randomized trial comparing RFA with stereotactic radiation therapy has been completed. However, future technical improvements in RFA have to focus on improved local safety [28]. The systemic progression rate after local tumor ablation in NSCLC is reported to be up to $40 \%$ in the literature; in our series, distant metastases developed in 32\% of the cases [29]. A thorough search for possible metastases preceding the local ablation - in our patients, this was accomplished with PET and cerebral CT or MRI - is therefore indispensable when considering local tumor ablation.

Given the risk profile of our patients and the duration of biopsy and frozen section examination, the need for mandatory histologic proof in all patients can be questioned. On the other hand, the potential of this combined approach is to avoid unnecessary therapies, e.g. in benign diseases (also with positive PET), and eventually to perform adequate subsequent adjuvant therapies based on histology. In high-risk patients without anticipated benefit of histology, RFA might be performed without histologic proof of malignancy based on the above-mentioned radiological criteria or due to clinical history [30,31].

\section{Conclusion}

Simultaneous CT-guided biopsy and RFA of solitary pulmonary lesions in high-risk patients is a safe procedure. The potential of this combined approach is to obtain a certain diagnosis, to avoid unnecessary therapies 
and eventually to perform adequate therapies based on histology. Taking the local progression rate into account, RFA should only be performed in those patients who are unable to or refuse to undergo surgery.

\section{Financial Disclosure and Conflicts of Interest}

Each author certifies having no conflict of interest with the submitted article.

\section{References}

-1 Mery CM, Pappas AN, Bueno R, Mentzer SJ, Lukanich JM, Sugarbaker DJ, Jaklitsch MT: Relationship between a history of antecedent cancer and the probability of malignancy for a solitary pulmonary nodule. Chest 2004; 125:2175-2181.

-2 Grgic A, Yuksel Y, Groschel A, Schafers HJ, Sybrecht GW, Kirsch CM, Hellwig D: Risk stratification of solitary pulmonary nodules by means of PET using ${ }^{18} \mathrm{~F}$-fluorodeoxyglucose and SUV quantification. Eur J Nucl Med Mol Imaging 2010;37:1087-1094.

- 3 Sakamoto M, Murakawa T, Kitano K, Murayama $\mathrm{T}$, Tsuchiya $\mathrm{T}$, Nakajima J: Resection of solitary pulmonary lesion is beneficial to patients with a history of malignancy. Ann Thorac Surg 2010;90:1766-1771.

-4 Janku F, Garrido-Laguna I, Petruzelka LB, Stewart DJ, Kurzrock R: Novel therapeutic targets in non-small cell lung cancer. J Thorac Oncol 2011;6:1601-1612.

-5 Deppen S, Putnam JB Jr, Andrade G, Speroff T, Nesbitt JC, Lambright ES, Massion PP, Walker R, Grogan EL: Accuracy of FDGPET to diagnose lung cancer in a region of endemic granulomatous disease. Ann Thorac Surg 2011;92:428-433.

6 Ambrosini V, Rubello D: Is there an ideal diagnostic algorithm in solitary pulmonary nodules? Respiration 2006;73:587-589.

7 Naalsund A, Maublant J: The solitary pulmonary nodule - is it malignant or benign? Diagnostic performance of Tc-depreotide SPECT. Respiration 2006;73:634-641.

-8 Eberhardt R, Ernst A, Herth FJ: Ultrasoundguided transbronchial biopsy of solitary pulmonary nodules less than $20 \mathrm{~mm}$. Eur Respir J 2009;34:1284-1287.

9 Eberhardt R, Kahn N, Gompelmann D, Schumann M, Heussel CP, Herth FJ: Lungpoint - a new approach to peripheral lesions. J Thorac Oncol 2010;5:1559-1563.

-10 Schwarz Y, Mehta AC, Ernst A, Herth F, Engel A, Besser D, Becker HD: Electromagnetic navigation during flexible bronchoscopy. Respiration 2003;70:516-522.

-11 Lu CH, Hsiao CH, Chang YC, Lee JM, Shih JY, Wu LA, Yu CJ, Liu HM, Shih TT, Yang PC: Percutaneous computed tomographyguided coaxial core biopsy for small pulmonary lesions with ground-glass attenuation. J Thorac Oncol 2012;7:143-150.

12 Eberhardt R, Morgan RK, Ernst A, Beyer T, Herth FJ: Comparison of suction catheter versus forceps biopsy for sampling of solitary pulmonary nodules guided by electromag- netic navigational bronchoscopy. Respiration 2010;79:54-60.

13 Lencioni R, Crocetti L, Cioni R, Suh R, Glenn D, Regge D, Helmberger T, Gillams AR, Frilling A, Ambrogi M, et al: Response to radiofrequency ablation of pulmonary tumours: a prospective, intention-to-treat, multicentre clinical trial (the rapture study). Lancet Oncol 2008;9:621-628.

14 Hiraki T, Gobara H, Mimura H, Matsui Y, Toyooka S, Kanazawa S: Percutaneous radiofrequency ablation of clinical stage I nonsmall cell lung cancer. J Thorac Cardiovasc Surg 2011;142:24-30.

15 Dadrich M, Schneider T, Puderbach M, Kauczor HU, Heussel CP: Moving pleural mass. Med Klin Intensivmed Notfmed 2012; 107:213-215.

16 Cheung YC, Chang JW, Hsieh JJ, Lin G, Tsai $\mathrm{YH}$ : Adequacy and complications of computed tomography-guided core needle biopsy on non-small cell lung cancers for epidermal growth factor receptor mutations demonstration: 18-gauge or 20-gauge biopsy needle. Lung Cancer 2010;67:166-169.

17 Yao X, Gomes MM, Tsao MS, Allen CJ, Geddie W, Sekhon H: Fine-needle aspiration biopsy versus core-needle biopsy in diagnosing lung cancer: a systematic review. Curr Oncol 2012;19:e16-e27.

18 Gould MK, Fletcher J, Iannettoni MD, Lynch WR, Midthun DE, Naidich DP, Ost DE: Evaluation of patients with pulmonary nodules: when is it lung cancer?: ACCP evidencebased clinical practice guidelines (2nd edition). Chest 2007;132:108S-130S

19 Laurent F, Latrabe V, Vergier B, Michel P: Percutaneous CT-guided biopsy of the lung: comparison between aspiration and automated cutting needles using a coaxial technique. Cardiovasc Intervent Radiol 2000;23: 266-272.

20 Anderson JM, Murchison J, Patel D: CTguided lung biopsy: factors influencing diagnostic yield and complication rate. Clin Radiol 2003;58:791-797.

21 Okuma T, Matsuoka T, Yamamoto A, Oyama Y, Hamamoto S, Toyoshima M, Nakamura K, Miki Y: Determinants of local progression after computed tomography-guided percutaneous radiofrequency ablation for unresectable lung tumors: 9-year experience in a single institution. Cardiovasc Intervent Radiol 2010;33:787-793.

22 Yasui K, Kanazawa S, Sano Y, Fujiwara T, Kagawa S, Mimura H, Dendo S, Mukai T, Fu- jiwara $\mathrm{H}$, Iguchi $\mathrm{T}$, et al: Thoracic tumors treated with CT-guided radiofrequency ablation: initial experience. Radiology 2004; 231:850-857.

-23 Fernando HC, De Hoyos A, Landreneau RJ Gilbert S, Gooding WE, Buenaventura PO, Christie NA, Belani C, Luketich JD: Radiofrequency ablation for the treatment of nonsmall cell lung cancer in marginal surgical candidates. J Thorac Cardiovasc Surg 2005. 129:639-644

24 Lanuti M, Sharma A, Digumarthy SR, Wright CD, Donahue DM, Wain JC, Mathisen DJ, Shepard JA: Radiofrequency ablation for treatment of medically inoperable stage I non-small cell lung cancer. J Thorac Cardiovasc Surg 2009;137:160-166.

25 Kishi K, Nakamura H, Kobayashi K, Hashimoto T, Hatao H, Oh-ishi S, Matsuoka T: Percutaneous CT-guided radiofrequency ablation of pulmonary malignant tumors: preliminary report. Intern Med 2006;45:65-72.

26 Timmerman R, Paulus R, Galvin J, Michalski J, Straube W, Bradley J, Fakiris A, Bezjak A, Videtic G, Johnstone D, et al: Stereotactic body radiation therapy for inoperable early stage lung cancer. JAMA 2006;303:1070-1076.

27 Onishi H, Shirato H, Nagata Y, Hiraoka M, Fujino M, Gomi K, Niibe Y, Karasawa K, Hayakawa K, Takai Y, et al: Hypofractionated stereotactic radiotherapy (HypoFXSRT) for stage I non-small cell lung cancer: updated results of 257 patients in a Japanese multi-institutional study. J Thorac Oncol 2007;2:S94-S100.

28 Dupuy DE: Image-guided thermal ablation of lung malignancies. Radiology 2011;260: 633-655.

29 Pennathur A, Luketich JD, Abbas G, Chen M, Fernando HC, Gooding WE, Schuchert MJ, Gilbert S, Christie NA, Landreneau RJ: Radiofrequency ablation for the treatment of stage I non-small cell lung cancer in highrisk patients. J Thorac Cardiovasc Surg 2007; 134:857-864

30 Zhu JC, Yan TD, Glenn D, Morris DL: Radiofrequency ablation of lung tumors: feasibility and safety. Ann Thorac Surg 2009;87:10231028.

-31 Yamakado K, Hase S, Matsuoka T, Tanigawa N, Nakatsuka A, Takaki H, Takao M, Inoue Y, Kanazawa S, Sawada S, et al: Radiofrequency ablation for the treatment of unresectable lung metastases in patients with colorectal cancer: a multicenter study in Japan. J Vasc Interv Radiol 2007;18:393-398. 